\title{
Treatment of childhood Hodgkin lymphoma in sub-Saharan Africa: A report from the French-African Paediatric Oncology Group (GFAOP)
}

F Traore, ${ }^{1} \mathrm{MD}$; F B Diagne Akonde, ${ }^{2} \mathrm{MD} ; \mathrm{B}$ Togo,${ }^{1} \mathrm{MD}$; C Moreira,${ }^{2} \mathrm{MD} ; \mathrm{N}$ M Rakotomahefa,${ }^{3} \mathrm{MD} ; \mathrm{A}$ Pondy ${ }^{4} \mathrm{MD}$; C Bouda, ${ }^{5} \mathrm{MD}$; M Harif, ${ }^{6} \mathrm{MD}$; F Eshun, ${ }^{7} \mathrm{MD}$; C Edan, ${ }^{8} \mathrm{MD}$

\author{
${ }^{1}$ Paediatric Department, Paediatric Oncology Unit, Gabriel Toure Hospital, Bamako, Mali \\ ${ }^{2}$ Paediatric Oncology Department, Aristide Le Dantec Hospital, Dakar, Senegal \\ ${ }^{3}$ Joseph Ravoahangy Andrianavalona Hospital, Antananarivo, Madagascar \\ ${ }^{4}$ Chantal Biya Foundation Hospital, Yaoundé, Cameroon \\ ${ }^{5}$ Yalgado Hospital, Ouagadougou, Burkina Faso \\ ${ }^{6}$ Hospital Marrakech, Morocco \\ ${ }^{7}$ Phoenix Children's Hospital, Phoenix, United States \\ ${ }^{8}$ Hospital de Rennes, Rennes, France
}

Corresponding author: F Traore (drfousseynitraore@gmail.com)

\begin{abstract}
Background. Childhood Hodgkin lymphoma (HL) is typically treated by chemo- and radiotherapy, depending on the stage of the disease. Studies on the treatment of HL by chemotherapy alone have shown encouraging results.

Objective. To evaluate the feasibility, epidemiological and therapeutic aspects of paediatric HL treated with only COPP/ABV hybrid chemotherapy (cyclophosphamide, vincristine, procarbazine, prednisone, adriamycin, bleomycin and vinblastine).

Methods. This was a prospective multicentre study on the management of HL in paediatric oncology centres of the French-African Paediatric Oncology Group in sub-Saharan Africa, from 1 October 2006 to 30 November 2012. To be included in the study, patients had to be younger than 18 years at diagnosis, with histologically proven HL.

Results. A total of 106 patients were included, with a median age of 10 years (range: 2 - 18 years). The sex ratio was 3.1, with a preponderance of male patients (male: $n=80$; female: $n=26$ ). The largest number of patients were in stage IIIB ( $n=47)$, IIB ( $n=18)$ and IVB $(n=15)$; other stages were represented to a lesser extent. More than $80 \%$ of patients had an unfavourable initial prognosis. On biopsy, the nodular sclerosis subtype was observed in $36 \%$ of patients $(n=38)$, followed by mixed cellularity $(n=21 ; 20 \%)$ and the lymphocyte-rich subtype $(n=17 ; 16 \%)$. Eighteen patients relapsed. The overall survival rate of treated patients was $82 \%$ at a median follow-up of 30 months. Conclusion. The treatment of childhood HL in sub-Saharan Africa is challenging. The use of a hybrid chemotherapy protocol alone can be effective at improving patient survival.
\end{abstract}

S Afr J Child Health 2020;14(3):155-160. https://doi.org/10.7196/SAJCH.2020.v14i3.1723

Hodgkin lymphoma (HL) is a B-cell line lymphoma, characterised histologically by the presence of large, atypical cells called ReedSternberg cells. The first histological description dates back to 1832 by Thomas Hodgkin. ${ }^{[1]}$ Epstein-Barr virus (EBV) is an important factor in the pathogenesis of HL and it is detected in Reed-Sternberg cells in the vast majority of HL specimens from developing countries, but much less frequently in high-income countries. ${ }^{[2]}$ The incidence of $\mathrm{HL}$ is 1.2 per 100000 children and represents the most common malignant tumour in adolescents in high-income countries, and the majority of cases are diagnosed at an early stage of disease. ${ }^{[3]}$ Hodgkin's disease is more common in children under 10 years of age in developing countries.

HL is a malignant but highly curable tumour and its treatment is one of the success stories of modern medicine. The use of chemotherapy combined with radiotherapy has greatly improved the survival rate of advanced stages of the disease. In high-income countries, the event-free survival and overall survival rates are $85 \%$ and $90 \%$, respectively. ${ }^{[4,5]}$
The reported results of therapy of HL in low- and middle-income countries (LMICs) are not as good, due to several factors. ${ }^{[6,7]}$ One of the key reasons is that radiation therapy centres in sub-Saharan Africa are rare, but efforts are underway to address this issue. ${ }^{[8,9]}$ Studies from one institution using chemotherapy alone in the treatment of HL have shown encouraging results. ${ }^{[10,11]}$

This therapeutic strategy has been adopted by the French-African Paediatric Oncology Group (GFAOP) to improve the treatment of children with HL in sub-Saharan Africa. In this article, we present the results of a prospective, collaborative, multicentre study on the management of HL using only chemotherapy in GFAOP institutions.

\section{Methods}

This was a prospective, multicentre study aimed at evaluating the feasibility of using only COPP/ABV hybrid chemotherapy (cyclophosphamide, vincristine, procarbazine, prednisone, adriamycin, bleomycin and vinblastine) in treating children diagnosed 
with $\mathrm{HL}$ and the associated epidemiological and therapeutic aspects. Patients from seven oncology centres of the GFAOP in sub-Saharan Africa were included. Participating centres were located in Burkina Faso, Cameroon, Mali, Madagascar and Senegal.

\section{Patient selection}

The study was conducted between 1 October 2006 and 30 November 2012. Patients younger than 18 years with histologically confirmed HL were enrolled in the study. The histological criteria established by the World Health Organization were used for the diagnosis. ${ }^{[12]}$ In addition, enrolled patients should not previously have been treated with chemotherapy or radiotherapy, had to be HIV negative and should not have had any major contraindication for treatments. Signed consent of the child's parents or legal guardian was obtained prior to their enrolment in the study.

All the patients underwent complete clinical examination, including reporting the number and size of superficial lymph nodes $(>1 \mathrm{~cm})$ on a body schema, measurement of liver and spleen size and a routine blood check. The blood analysis included complete blood count, erythrocyte sedimentation rate, Rhesus grouping, renal and hepatic function tests, an HIV test and a hepatitis B (HbsAg) test. Echocardiography, chest X-rays (CXR) with the mediastinal-thoracic index (MTI) measured $(\geq 0.45$ considered a large mediastinum), abdominal ultrasound, chest-abdominal computed tomography scan (if possible and repeatable), bone marrow aspiration and biopsy were performed in all patients enrolled in the study. The staging of patients was performed according to the Ann Arbor classification. ${ }^{[13]}$ The letter B was added as suffix to the stage of patients if weight loss $(>10 \%$ of the weight of the body during the last 6 months) or fever $\left(>38^{\circ} \mathrm{C}\right.$ for at least a week or night sweats) was observed. The absence of these signs was noted by the suffix A on the stage of disease.

Patients were divided into two treatment groups according to the prognosis at initial diagnosis: favourable (G1) and unfavourable (G2).

The criteria for group G1 were: stages I and IIA, MTI $<0.45$, lymphadenopathy $<6 \mathrm{~cm}$, and no contiguous involvement. Criteria for group G2 were: stages IIB, III or IV, MTI $\geq 0.45$, lymphadenopathy $\geq 6 \mathrm{~cm}$ or presence of visceral involvement.

\section{Chemotherapy strategies}

The treatment strategy was based on GFAOP guidelines for the treatment of HL. All patients received COPP/ABV hybrid chemotherapy according to their assigned therapeutic group and the response at evaluation. Chemotherapy was administered as follows: vincristine $1.5 \mathrm{mg} / \mathrm{m}^{2}$ intravenously and cyclophosphamide
$650 \mathrm{mg} / \mathrm{m}^{2}$ intravenously on day 1 , procarbazine $100 \mathrm{mg} / \mathrm{m}^{2}$ orally on days $1-8$, adriamycin $35 \mathrm{mg} / \mathrm{m}^{2}$, vinblastine $6 \mathrm{mg} / \mathrm{m}^{2}$ and bleomycin $10 \mathrm{mg} / \mathrm{m}^{2}$ all intravenously on day 8 , and prednisone $40 \mathrm{mg} / \mathrm{m}^{2}$ orally on days $1-14$ (Fig. 1). The effectiveness of the treatment was evaluated after every two cycles of chemotherapy by physical examination, CXR and abdominal ultrasound.

\section{Treatment of patients with a favourable prognosis at diagnosis (group G1)}

All patients in this group received two COPP/ABV courses followed by an evaluation. Good responders to treatment received two further cycles of therapy according to the protocol. After the first assessment, poor responders received two additional COPP/ABV courses, followed by a second assessment. If an insufficient response was found at this second evaluation, the treatment was stopped. If a good response was found, patients received two complementary courses and then treatment was stopped (Fig. 2).

\section{Treatment of patients with an unfavourable prognosis at diagnosis (group G2)}

All patients received two COPP/ABV courses followed by an evaluation. Good responders to treatment received four additional cycles of chemotherapy, after which treatment was stopped. Patients who did not respond well at the first assessment received two additional COPP/ABV courses. Continuation of therapy was decided at a subsequent evaluation. If the response was deemed to be good after this second round of treatment, another four courses were administered and then treatment was stopped (Fig. 3).

\section{Response criteria}

Complete remission was defined as the disappearance of all clinical, biological and visual signs of disease on imaging. A good response was defined as a $75 \%$ reduction of the sum of the diameters of all measurable lesions. Partial remission was defined as the disappearance of the biological and clinical signs and a reduction of at least $50 \%$ of all measurable targets. Tumour progression was defined as an increase of more than $25 \%$ in the size of at least one measurable lesion or the reappearance of the general signs. Patients who achieved complete remission or showed good response to the treatment were defined as good responders. Biopsy and histological examination confirmed relapse.

Assessment after treatment had been completed included a full physical examination, a CXR and abdominal ultrasound. The schedule of surveillance after the complete treatment was every 6 weeks during the first 6 months, then every 3 months until 1 year

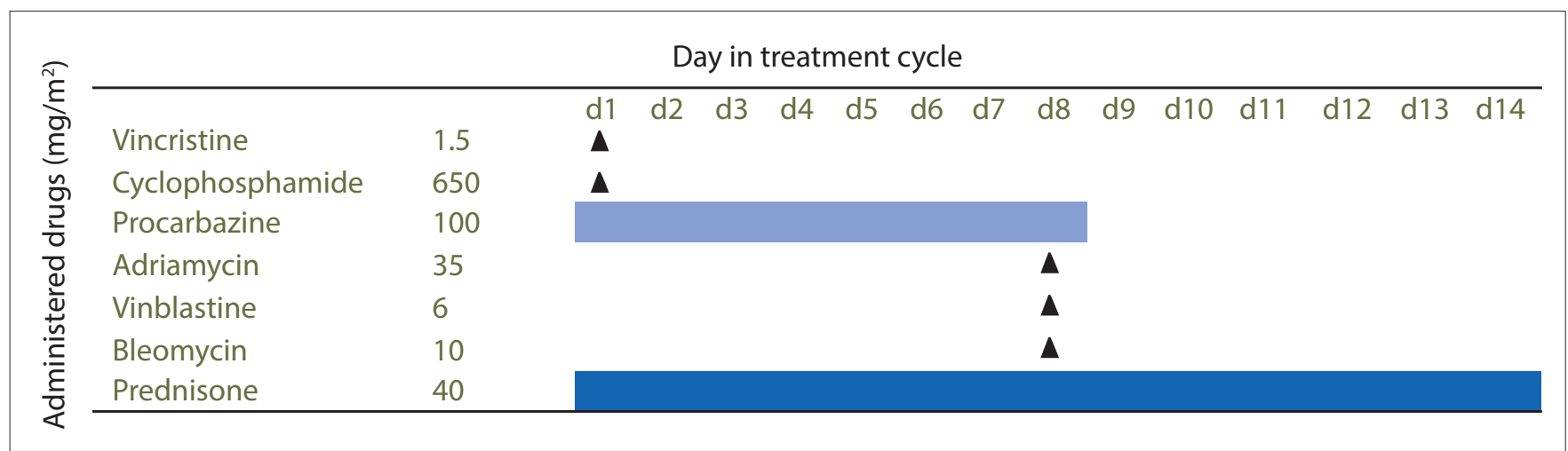

Fig. 1. $C O P P / A B V$ chemotherapy regimen. (COPP = cyclophosphamide, vincristine, prednisone, procarbazine; $A B V=$ adriamycin, bleomycin, vincristine. $)$ 


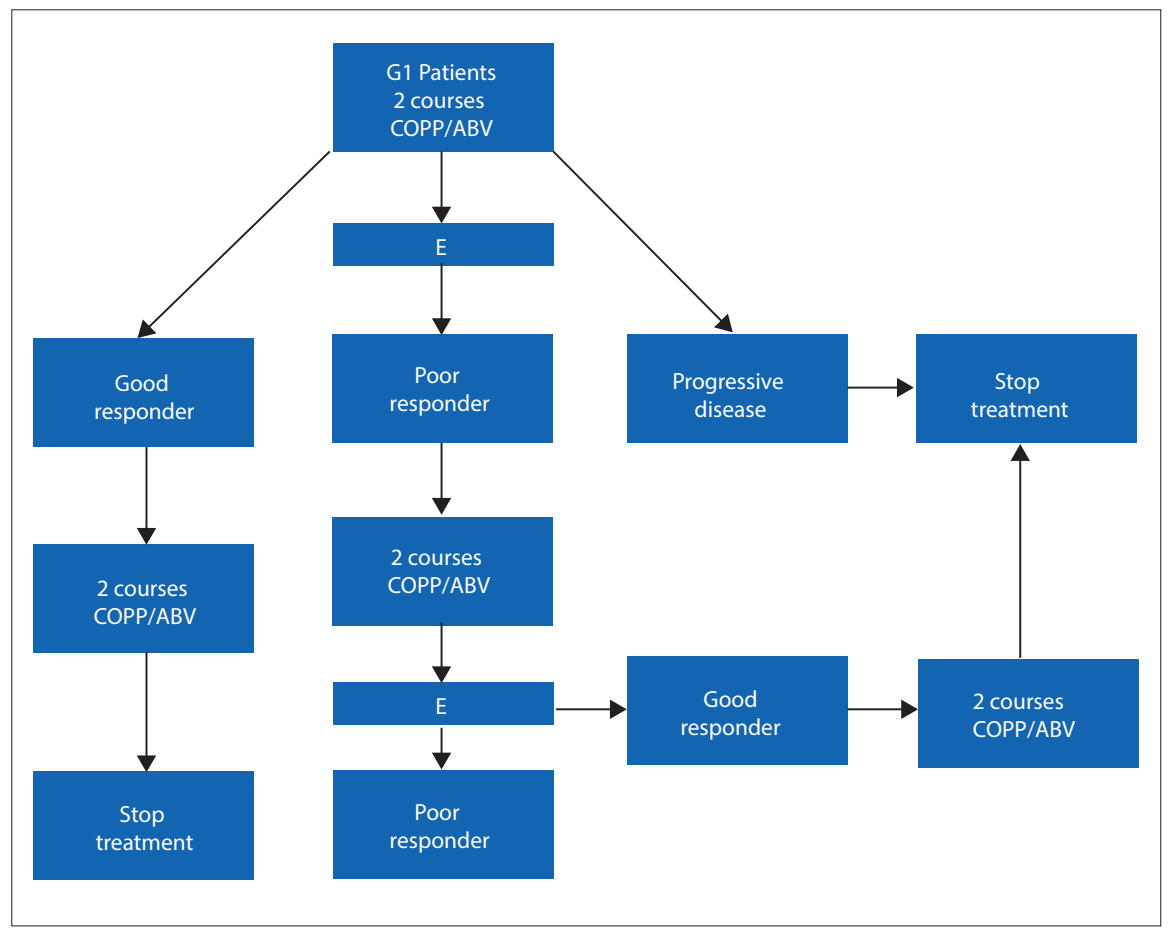

Fig. 2. Treatment schedule of patients with a favourable prognosis (group G1). (COPP = cyclophosphamide, vincristine, prednisone, procarbazine; $A B V=$ adriamycine, bleomycine, vincristine; $E=$ evaluation of disease.)

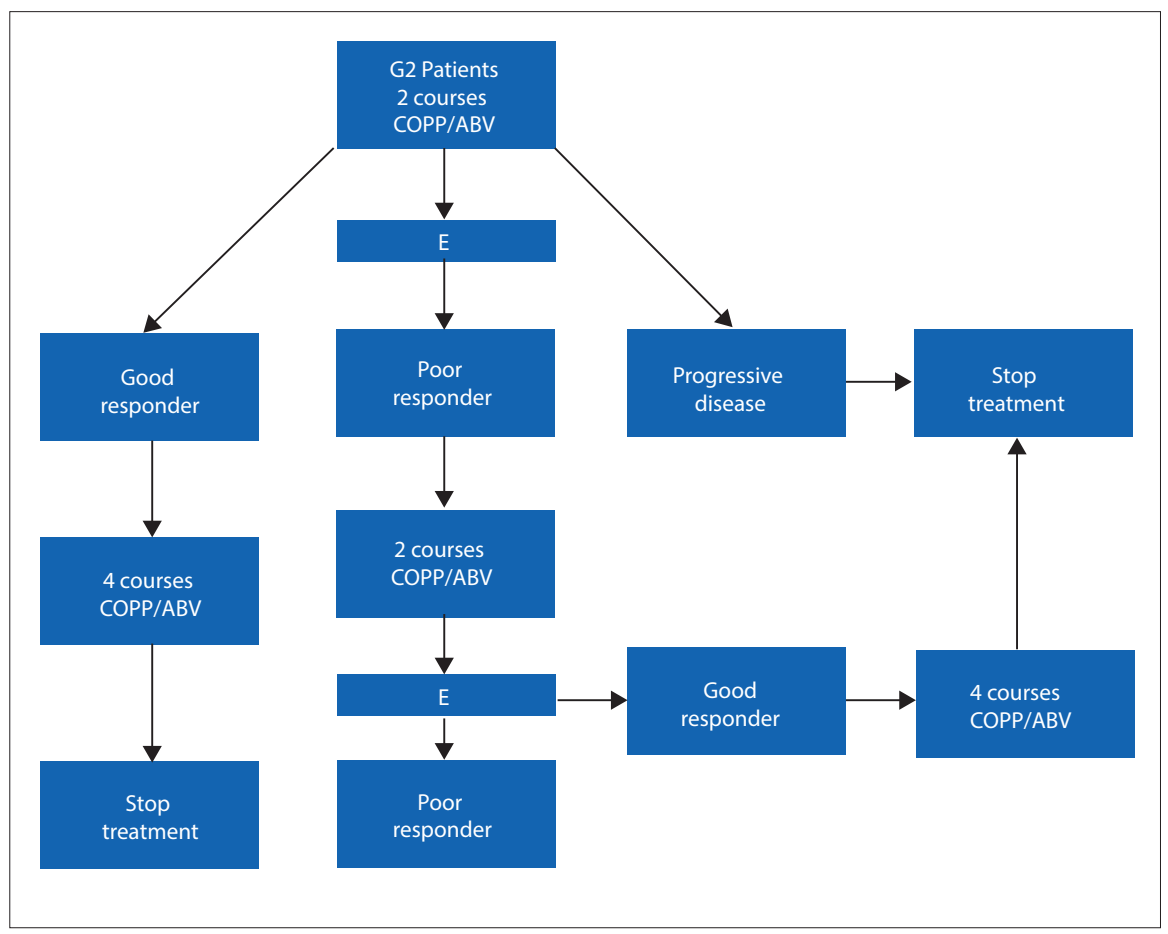

Fig. 3. Treatment schedule of patients with an unfavourable prognosis (group G2).(COPP=cyclophosphamide, vincristine, prednisone, procarbazine; $A B V=$ adriamycin, bleomycin, vincristine; $E=$ evaluation of disease.)

after the end of treatment, and then once a year.

\section{Data collection and analysis}

Each centre sent their collected data electronically to the GFAOP data manager. Data were analysed in SPSS version 20 (IBM
Corp., USA). The Kaplan-Meier method was used to estimate survival and the logrank test to compare the survival of different groups of treated patients. ${ }^{[14]}$

\section{Ethical considerations}

The consent of the patient's legal guardian was obtained before enrolment in the study. The ethics committees of each participating country gave their consent for the study.

\section{Results}

A total of 127 patients were registered for the study, of whom 21 patients were excluded for the following reasons: two cases of undifferentiated carcinoma of nasopharyngeal type; one case of nodular paragranuloma; one case of anaplastic lymphoma; one case of lymph node metastasis of a melanoma; patients previously treated by another protocol $(n=6)$; incomplete data $(n=7)$; one case of cardiomyopathy; one case of association of HL with tuberculosis; and one case of unknown reason. No HIV-positive cases were found.

The remaining 106 patients were therefore included in the analysis. The distribution of patients according to their country of origin was as follows: Senegal: $n=45$ (42.5\%); Mali: $n=26$ (24.5\%); Madagascar: $n=25$ (23.6\%); Cameroon: $n=6$ (5.7\%); Burkina Faso: $n=4$ (3.8\%).

The median age of patients was 10 years (range $2-18$ years). The age group $5-10$ years was the best represented $(n=41 ; 38.7 \%)$, followed by the group $10-14$ years $(n=35$; $33 \%$ ). The sex ratio was 3.1 (female: $n=26$; male: $n=80$ ). The largest number of patients were classified as stage IIIB $(n=47)$ and represented $44 \%$ of the study population; others were classified as stage IA $(n=2)$, IB $(n=7)$, IIA $(n=6)$, IIB $(n=18)$, IIIA $(n=8)$, IVA $(n=3)$ and IVB $(n=15)$.

G2 patients accounted for $85.8 \%$ of the study population $(n=91)$ and G1 patients for $14.2 \%(n=15)$. Histological diagnosis was performed by lymph node biopsy in all patients $(n=106 ; 100 \%)$, with the following subtypes identified: nodular sclerosis $(n=38 ; 36 \%)$, mixed cellularity $(n=21 ; 20 \%)$, lymphocyte-rich subtype ( $n=17 ; 16 \%)$, lymphocyte-depleted subtype $(n=2 ; 2 \%)$, and unknown type $(n=28 ; 26 \%)$. All patients received protocol-defined chemotherapy courses.

\section{Response to treatment}

After two cycles of chemotherapy, 90 patients were evaluated by physical examimation and imaging (CXR and abdominal ultrasonography). Of these, 80 patients were considered to be good responders and 10 were poor responders. The intermediate evaluation after four cycles of chemotherapy found 72 cases of good response and 5 cases of insufficient response. After six cycles, 51 patients were deemed to have responsed well and 4 patients showed insufficient 
response. At the end of treatment, 44 patients were considered to have responded well and 4 patients were deemed poor responders.

\section{Toxicity of COPP/ABV treatment}

Grade III anaemia with haemoglobin $<5 \mathrm{~g}$ dL was observed in 15 patients. Grade III neutropenia, with a neutrophil count $<500 \mathrm{~mm}^{3}$ was observed in 13 patients. One patient developed severe and prolonged pancytopenia. Sixteen patients had a severe infection associated with neutropenia. Pneumonia was noted in seven patients and urinary tract infection also in seven patients. Two patients developed severe sepsis at the end of treatment, and subsequently died. All the urinary tract infections were associated with Escherichia coli, as was one case of sepsis. Plasmodium falciparum malaria was diagnosed in two cases. The outcome of these infectious episodes was favourable, except for the two cases of sepsis. One case of grade III vomiting was noted. One case of dilated cardiomyopathy was noted and led to the withdrawal of adriamycin from the patient's treatment.

\section{Relapses}

A total of 17 patients relapsed. The median time to relapse was 13 months (range 4 41 months). Of these patients, 15 were from group G2 (unfavourable prognosis at diagnosis); 11 of these patients were in stage IIIB and 4 were in stage IVB. Two patients of group G1 (favourable initial prognosis) relapsed. One of these patients was 2 years old at diagnosis, had chronic otitis and a primary immune system deficiency was subsequently diagnosed; the second was 17 years old and was retrospectively diagnosed with bulky disease. This patient was erroneously assigned to the group with favourable prognoses. All cases of relapse were confirmed by biopsy. The initial treatment was completed in 12 patients before relapse and interrupted in 5 patients on medical decision. Seventeen patients presented with a relapse site identical to that involved at initial diagnosis. One patient, who was in stage IVB with liver involvement, had an isolated splenic relapse, which was different from the site of initial diagnosis. In the cohort of patients who relapsed, seven had bulky disease at diagnosis.

Second-line chemotherapy treatment was used to treat seven patients, two of whom are still in a second stable remission.

\section{Deaths}

A total of 20 deaths (18.9\%) were recorded, of which four were toxic deaths: a 16-yearold stage IIIB patient, splenectomised at diagnosis and in complete remission, died of a severe neurological form of malaria 7 months after completing treatment; one patient with a multidrug-resistant E. coli infection died at the end of the treatment; a 9-year-old patient with stage IIIB HL died during treatment owing to multidrugresistant tuberculosis; and an 11-year-old patient with stage IIIB HL died owing to severe digestive and haematologic toxicity. Sixteen patients died after relapse.

\section{Outcome}

At the final treatment assessment, the eventfree and overall survival rates were $67 \%$ and $82 \%$, respectively, at a median follow-up of 30 months (Fig. 4).

\section{Discussion}

$\mathrm{HL}$ in children is a poorly studied cancer in sub-Saharan Africa, with little data available on its treatment. It is possible that the frequency of the disease is underestimated because of difficulties in histological diagnosis.

HL is a highly curable disease, but unfortunately there are many challenges related to histological diagnosis, metastatic work-up and treatment in sub-Saharan Africa. Our study included patients with histological diagnosis of $\mathrm{HL}$ and who received treatment over a period of 6 years. In high-income countries, HL is typically a disease of teenagers and young adults, with a peak frequency in the 17 - 19-year age groups ${ }^{[15]} \mathrm{HL}$ appears to occur at an earlier age in developing countries than in high-income countries. ${ }^{[16,17]}$ In our series, the median age was 10 years (range: 2 - 18 years), with a predominance of children between 5 and 10 years $(n=41 ; 38.7 \%)$. In studies from
Morocco and India, the age group 6 - 14 years was the most affected. ${ }^{[18,19]}$ The early onset of $\mathrm{HL}$ in children in LMICs is thought to be due to early infection with EBV, although the role of the virus in the pathogenesis of $\mathrm{HL}$ remains partly enigmatic. ${ }^{[20,21]} \mathrm{EBV}$ was found in $68 \%$ and $93 \%$ of paediatric HL cases in South Africa and Malaysia, respectively. ${ }^{[22,23]}$ An association of HL with EBV infection was also found in Mexico and Peru. ${ }^{[24,25]}$ The male preponderance found in our series (76\%) is similar to what has been reported elsewhere in literature. ${ }^{[26,27]}$ In LMICs, the advanced disease stages seen in patients are likely due to late diagnosis and late referral. ${ }^{[28,29]}$ In our series, $44 \%$ of patients were identified to be in stage IIIB, and the group with an unfavourable prognosis (G2) accounted for $85.8 \%$ of patients. In studies from Brazil and India, stages III and IV accounted for $\sim 50 \%$ of patients. ${ }^{[30,31]}$

It is important to note that there was no centralised review of histology in this study; ideas for including such a review in future studies are beign considered. Mixed cellularity $\mathrm{HL}$ is the predominant histologic subtype of HL in LMICs, and thought to be associated with low socioeconomic conditions and early EBV infection. ${ }^{[32,33]}$ In contrast, the nodular sclerosis form is predominantly seen in high-income countries. However, we found $36 \%$ nodular sclerosis forms and $20 \%$ mixed cellularity forms. It should be noted that a significant proportion of histological subtypes were not specified. In high-income countries, the overall survival rate of HL treatment with combined chemo- and radiotherapy is greater than $90 \% \cdot{ }^{[34-36]}$ The aim of current protocols for the treatment of $\mathrm{HL}$ is to substitute alkylating agents and reduce the

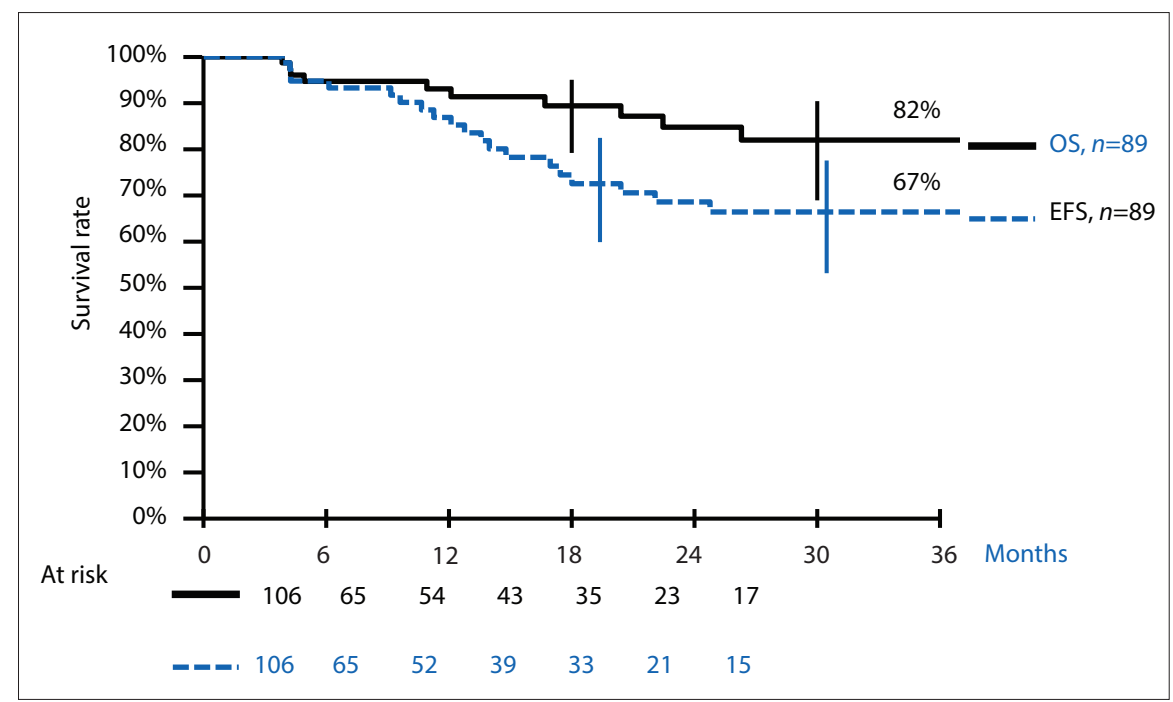

Fig. 4. Overall and event-free survival rates of treated patients. (OS = overall survival; EFS = event-free survival.) 
use of radiotherapy for early stages of disease, which respond well to initial chemotherapy. ${ }^{[37]}$ The current European protocols indicate radiotherapy for the territories initially affected according to the therapeutic response. Application of 18-fluorodeoxyglucose positron emission tomography (FDG-PET) is useful for assessing the initial response to treatment and therefore to determine the use of radiotherapy. ${ }^{[38]}$ Radiotherapy is available in North Africa and South Africa, and overall survival rates for HL are greater than $80 \%$.

Our study was conducted in sub-Saharan African countries with very low incomes. The anticancer drugs were graciously donated by the GFAOP. For a sustainable treatment of paediatric cancers, each GFAOP partner country must ensure the supply of anticancer drugs to support the development of paediatric oncology. Delayed diagnosis, inaccessibility to chemotherapy and unavailability of radiotherapy are the main obstacles in the treatment of HL. ${ }^{[39]}$ It has been known for many years that using chemotherapy alone is effective in curing HL, supported by evidence from countries with no availability or access to radiotherapy. At the time of this study, radiotherapy was not available in the countries that participated in this multicentre study.

The choice of the hybrid COPP/ABV chemotherapy protocol was based mainly on the remarkable results with regard to tolerance and efficacy obtained with this approach in LMICs. ${ }^{[40,41]}$ Three-year event-free survival in the Baez series in Nicaragua was found to be $100 \%$ for stages I, II and IIIA, and $74.9 \%$ for stage IIIB. ${ }^{[10]}$ In our series, we found an overall survival rate of $82 \%$ and an event-free survival rate of $67 \%$ across all stages combined after 30 months of follow-up. A better initial risk stratification and early evaluation of the therapeutic response of patients can improve overall survival. The low level of supportive care has a major influence on the outcomes of childhood cancer treatment in sub-Saharan Africa, partly explaining the difference between the overall survival rate in our study and that seen in Nicaragua when the same therapeutic strategy was used. In a study from Egypt, the event-free survival rate was found to be $96.6 \%$ with a protocol based on chemotherapy and radiotherapy. ${ }^{[42]}$ In our series, the toxicity of chemotherapy was haematologic, resulting in anaemia and neutropenia. Four toxic deaths were noted and were due to issues with supportive care.

The median time to relapse was 13 months. The majority of patients who relapsed were considered good responders at the first assessment. We did not find a statistically significant correlation between the histological subtype and the occurrence of relapse $(p=0.72)$. Second stable remission was obtained in two patients by second-line chemotherapy. Late relapse seems to be a better prognosis according to some authors. ${ }^{[43]}$ In this study, the number of patients lost to follow-up during treatment was not significant.

\section{Conclusion}

This study demonstrates the feasibility of using chemotherapy alone as an effective strategy for treating HL in sub-Saharan Africa, as shown in multiple centres. The enhancement of supportive care and the availability of radiotherapy centres will lead to better results. It is important to improve the initial stratification but also the early evaluation of the therapeutic response of patients.

\section{Declaration. None.}

Acknowledgements. The authors thank the GFAOP and its sponsors for their support in the development of paediatric oncology in Africa, Dr Marie Anne Raquin from GFAOP and the Gustave Roussy Institute (Paris, France), Prof. Hervé Rubie of Toulouse Hospital (Toulouse, France), and Dr Souad Nafa-Bruneau of GFAOP and the Gustave Roussy Institute (Paris, France).
Author contributions. CE conceived and designed the study. FT and FBDA analysed and interpreted the data. FT was responsible for literature review and writing the manuscript. All authors contributed to the intellectual content of the manuscript.

Funding. None.

Conflicts of interest. None.

1. Hodgkin T. On some morbid appearances of the absorbent glands and spleen. Med Chir Trans 1832;17:68-114. https://doi. org/10.1177/095952873201700106

2. Chang KL, Albujar PF, Chen YY, Johnson RM, Weiss LM. High prevalence of Epstein-Barr virus in the Reed-Sternberg cells of Hodgkin's disease occurring in Peru. Blood 1993;81:496-501

3. Dinand V, Arya LS. Epidemiology of childhood Hodgkins disease: Is it different in developing countries? Indian Pediatr 2006;43(2):141-147.

4. Diehl V, Thomas RK, Re D. Part II: Hodgkin's lymphoma - Diagnosis and treatment. Lancet Oncol 2004;5(1):19-26. https://doi.org/10.1016/s14702045(03)01320-2

5. Allemani C, Sant M, De Angelis R, Marcos-Gragera R, Coeberg JW, EUROCARE Working group. Hodgkin disease survival in Europe and the U.S.: Prognostic significance of morphologic groups. Cancer 2006;107(2):352360. https://doi.org/10.1002/cncr.21995

6. Hsu SC, Metzger ML, Hudson MM, et al. Comparison of treatment outcomes of childhood Hodgkin lymphoma in two US centers and a center in Recife, Brazil. Pediatr Blood Cancer 2007;49(2):139-144. https://doi.org/10.1002/ pbc. 20883

7. Jacobs P, King HS, Karabus C, Hartley P, Werner D. Hodgkin's disease in children. A ten-year experience in South Africa. Cancer 1984;53:210-213.

8. Khanfir A, Toumia N, Masmoudia A, et al. Pediatric Hodgkin disease in south Tunisia: A study of 23 cases. Cancer Radiother 2007;11(5):241-246. https://doi.org/10.1016/j.canrad.2007.05.002

9. Stefan DC. Hodgkin lymphoma in Africa: Present and future. Transfus Apher Sci 2013;49(2):144-146. https://doi.org/10.1016/j.transci.2013.07.016

10. Baez F, Ocampo E, Conter V, et al. Treatment of childhood Hodgkin's disease with COPP or COPP-ABV (hybrid) without radiotherapy in Nicaragua. Ann Oncol 1997;8(3):247-250. https://doi.org/10.1023/a:1008200210674

11. Sagar TG, Chandra A, Raman SG. Childhood Hodgkin disease treated with COPP/ABV hybrid chemotherapy: A progress report. Med Pediatr Oncol 2003(1);40:66-69. https://doi.org/10.1002/mpo.10017

12. Harris NL, Jaffe ES, Diebold J, et al. World Health Organization classification of neoplastic diseases of the hematopoietic and lymphoid tissues: Report of the clinical advisory committee meeting - Airlie house, Virginia, November 1997. J Clin Oncol 1999;17(12):3835-3849. https://doi.org/10.1200/ jco.1999.17.12.3835

13. Lister TA, Crowther D, Sutcliffe SB, et al. Report of a committee convened to discuss the evaluation and staging of patients with Hodgkin's disease: Cotswolds meeting. J Clin Oncol 1989;7(11):1630-1636. https://doi. org/10.1200/jco.1989.7.11.1630

14. Kaplan EL, Meier P. Nonparametric estimation from incomplete observations. J Am Stat Assoc 1958;53(28):457-481.

15. Punnett A, Tsang RW, Hodgson DC. Hodgkin lymphoma across the age spectrum: Epidemiology, therapy, and late effects. Semin Radiat Oncol 2010;20(1):30-44. https://doi.org/10.1016/j.semradonc.2009.09.006

16. Metzger M, Krosin MJ, Hudson MM, et al. Hodgkin lymphoma. In: Pizzo PA, Poplack DG, eds. Principles and Practice of Pediatric Oncology. 6th ed. Philadelphia: Wolters Kluwer/Lippincott Williams \& Wilkins, 2011:639-662.

17. Radhakrishnan V, Dhanushkodi M, Ganesan TS, et al. Pediatric Hodgkin lymphoma treated at cancer institute, Chennai, India: Long term outcome. J Glob Oncol 2017;3(5):545-554. https://doi.org/10.1200/jgo.2016.005314

18. Harif M, Madani A, Hessissen L, et al. Childhood Hodgkin's disease in Morocco. Arch Pediatr 2009;16(6):675-677. https://doi.org/10.1016/s0929693x(09)74108-9

19. Arya LS, Dinand V, Thavaraj V, et al. Hodgkin's disease in Indian children: Outcome with chemotherapy alone. Pediatr Blood Cancer 2006;46(1):26-34. https://doi.org/10.1002/pbc.20157

20. Weinreb M, Day PJ, Niggli F, et al. The role of Epstein-Barr virus in Hodgkin's disease from different geographical areas. Arch Dis Child 1996;74(1):27-31. https://doi.org/10.1136/adc.74.1.27

21. Weinreb M, Day PJ, Niggli F, et al. The consistent association between Epstein-Barr virus and Hodgkin's disease in children in Kenya. Blood 1996;87(9):3828-3836.

22. Engel M, Essop MF, Close P, Hartley P, Pallesen G, Sinclair-Smith C. Improved prognosis of Epstein-Barr virus associated childhood Hodgkin's lymphoma: Study of 47 South African cases. J Clin Pathol 2000;53(3):182-186. https:// doi.org/10.1136/jcp.53.3.182

23. Peh SC, Looi LM, Pallesen G. Epstein-Barr virus (EBV) and Hodgkin's disease in a multi-ethnic population in Malaysia. Histopathology 1997;30(3):227233. https://doi.org/10.1046/j.1365-2559.1997.d01-594.x 
24. Palma I, Sánchez AE, Jiménez-Hernández E, et al. Detection of EpsteinBarr virus and genotyping based on EBNA2 protein in Mexican patients with Hodgkin lymphoma: A comparative study in children and adults. Clin Lymphoma Myeloma Leuk 2013;13(3):266-272. https://doi.org/10.1016/j. clml.2012.11.010

25. Chang KL, Albújar PF, Chen YY, Johnson RM, Weiss LM. High prevalence of Epstein-Barr virus in the Reed-Sternberg cells of Hodgkin's disease occurring in Peru. Blood 1993;81(2):496-501.

26. Mauz-Körholz C, Metzger ML, Kelly KM, et al. Pediatric Hodgkin lymphoma. J Clin Oncol 2015;33(27):2975-2985. https://doi.org/10.1200/jco.2014.59.4853

27. Shanbhag S, Ambinder RF. Hodgkin lymphoma: A review and update on recent progress. CA Cancer J Clin 2018;68(2):116-132. https://doi.org/10.3322/ caac. 21438

28. Chukwu BF, Ezenwosu OU, Ikefuna AN, Emodi IJ. Diagnostic delay in pediatric cancer in Enugu, Nigeria: A prospective study. Pediatr Hematol Oncol 2015;32(2):164-171. https://doi.org/10.3109/08880018.2014.957368

29. Hadley LG, Rouma BS, Saad-Eldin Y. Challenge of pediatric oncology in Africa. Semin Pediatr Surg 2012;21(2):136-141. https://doi.org/10.1053/j. sempedsurg.2012.01.006

30. Trehan A, Singla S, Marwaha RK, Bansal D, Srinivasan R. Hodgkin lymphoma in children: Experience in a tertiary care centre in India. J Pediatr Hematol Oncol 2013;35(3):174-179. https://doi.org/10.1097/mph.0b013e318271f587

31. Faria SL, Vassallo J, Cosset JM, Brandalise SR. Childhood Hodgkin's disease in Campinas, Brazil. Med Pediatr Oncol 1996;26(2):90-94. https://doi. org/10.1002/(SICI)1096-911X(199602)26:2<90::AID-MPO4>3.0.CO;2-P

32. Barros MH, Hassan R, Niedobitek G. Disease patterns in pediatric classical Hodgkin lymphoma: A report from a developing area in Brazil. Hematol Oncol 2011;29(4):190-195. https://doi.org/10.1002/hon.984

33. Hemsrichart V, Pintong J. Association of the Epstein-Barr viruses with Hodgkin lymphoma: An analysis of pediatric cases in Thailand. J Med Assoc Thai 2005;88(6):782-787.

34. Schellong G, Brämswig JH, Hörnig-Franz I. Treatment of children with Hodgkin's disease: Results of the German Pediatric Oncology Group. Ann Oncol 1992;3 Suppl 4:73-76. https://doi.org/10.1093/annonc/3.suppl_4.s73
35. Wolden SL, Chen L, Kelly KM, et al. Long-term results of CCG 5942: A randomized comparison of chemotherapy with and without radiotherapy for children with Hodgkin's lymphoma - a report from the Children's Oncology Group. J Clin Oncol 2012;30(26):3174-3180. https://doi.org/10.1200/JCO.2011.41.1819

36. Seror E, Donadieu J, Pacquement $\mathrm{H}$, et al. Combined therapy in children and adolescents with classical Hodgkin's lymphoma: A report from the SFCE on MDH-03 national guidelines. Pediatr Hematol Oncol 2016;33(7-8):423-437. https://doi.org/10.1080/08880018.2016.1247393

37. Oberlin O, Habrand JL, Schaison G, et al. Hodgkin's disease in children. Current therapeutic strategies. Bull Cancer 1988;75(1):53-60.

38. Kluge R, Körholz D. Role of FDG-PET in staging and therapy of children with Hodgkin lymphoma. Klin Padiatr 2011;223(6):315-319. https://doi. org/10.1055/s-0031-1287834

39. Harif M, Traoré F, Hessissen L, Moreira C, Atteby JJ. Challenges for paediatric oncology in Africa. Lancet Oncol 2013;14(4):279-281.

40. Sripada PV, Tenali SG, Vasudevan M, Viswanadhan S, Sriraman D, Kandasamy R. Hybrid (COPP/ABV) therapy in childhood Hodgkin's disease: A study of 53 cases during 1989-1993 at the Cancer Institute, Madras. Pediatr Hematol Oncol 1995;12(4):333-341. https://doi.org/10.3109/08880019509029583

41. Klumb CE, Carriço MK, De Rezende LM, et al. Long-term outcome of children and adolescents treated with the COPP-ABV hybrid protocol for Hodgkin's disease: Balance of risks. Clin Oncol (R Coll Radiol) 2007;19(8):628-629. https:// doi.org/10.1016/j.clon.2007.06.010

42. Sherief LM, Elsafy UR, Abdelkhalek ER, et al. Hodgkin lymphoma in childhood: Clinicopathological features and therapy outcome at 2 centers from a developing country. Medicine (Baltimore) 2015;94(15):e670. https://doi.org/10.1097/ md.0000000000000670

43. Harker-Murra PD, Drachtman RA, Hodgson DC, Chauvenet AR, Kelly KM, Cole PD. Stratification of treatment intensity in relapsed pediatric Hodgkin lymphoma. Pediatr Blood Cancer 2014;61(4):579-586. https://doi.org/10.1002/ pbc. 24851

Accepted 3 March 2020 